\title{
月水収支分析のための \\ 基準蒸発散量推定式の検討 \\ CALIBRATION OF REFERENCE EVAPOTRANSRATION EQUATION FOR MONTHLY WATER BALANCE ANALYSIS IN JAPAN
}

\author{
松井 宏之 \\ Hiroyuki MATSUI \\ 正会員 修 (農) 宇都宮大学助手 農学部農業環境工学科（テ321-8505 杤木県宇都宮市峰町350）
}

\begin{abstract}
The Hargreaves equation has two parameters: one is an empirical coefficient for estimating solar radiation, and the other is a fitting parameter. This study aims to develop the calibration equation for the fitting parameter, which is useful to analyze monthly water balance throughout Japan. The followings are clarified: 1) the fitting parameter is estimated by a multiple linear regression model with the square root of the annual mean range between mean monthly maximum and minimum temperatures, the proximity to a coast, and the annual mean temperature; 2) the modified Hargreaves equation with the above-mentioned model gives a good estimation accuracy with a root mean square error of $0.34 \mathrm{~mm} \pm 0.10 \mathrm{~mm}$ (Ave. \pm S.D.).
\end{abstract}

Key Words : Hargreaves, Penman-Monteith, stepwise multiple regression analysis

\section{1.はじめに}

わが国において利用される水のうち, 総量の9割程度 は河川を水源としている，その河川の流況が，現在まで どのように推移してきたか, 今後どのように推移するか, を検討することは重要な課題である．長年にわたる河川 流量データが蓄積されていれば, 前者の分析は容易に行 うことができる．しかし，検討したい流域において流量 観測が行われていない，長期にわたるデータの蓄積がな いなどの理由により，長期変動の分析が困難になること がある. こうしたとき, 河川流量は, 降水量, 可能蒸発 散量を入力データとする何らかの水文流出モデルによっ て算出されることが多い.これら入力データのうち降水 量は古くから数多くの観測地点があるが，可能蒸発散量 は何らかの式によって推定せざるを得ない．

一般に可能蒸発散量は, Penman式あるいはPenman式 を基礎とする式によって推定されることが多い. しかし， Penman式の適用には，全天日射量（あるいは日照時間, 雲量)，気温，湿度，風速が不可欠であり，適用可能な 地点, 期間には限界がある. そのため, 長期にわたり可 能蒸発散量を求めるときには，気温データのみで基準蒸 発散量を算出するThornthwaite ${ }^{1)}$ やHamon ${ }^{2)}$ により導かれ た経験的な式を用いることが多い。これに対し，
Hargreaves et al. ${ }^{3)}$ は, ライシメータによる基淮蒸発散量が 全天日射量に気温を乗じた値と高い相関を持つこと，さ らに全天日射量が大気外日射量に気温較差の平方根を乗 じた值と高い相関をもつことを示し，気温データだけを 用いる簡便な基隻蒸発散量推定式を導いている. Jensen et al. ${ }^{4}$ は, Penman-Monteith式による基準蒸発散量を真值 としたとき, Hargreaves式が10日平均, 月平均の基隻蒸 発散量を精度よく推定することを示している.

河川流況の長期的な変動を検討する際，対象となる流 量データが日単位ではなく月単位であっても，その目的 を達することは十分に可能であると考えられる. そこで， 月水収支分析における蒸発散量の推定精度を向上させる ため, Hargreaves式に着目し，わが国に適応する係数に ついて検討した. さらに, 原式との比較, Thornthwaite 式やHamon式との比較を通じて, 適応させたHargreaves 式の有用性について検証した.

\section{2. 基準蒸発散量の推定式}

Hargreaves式の係数を適応させるためには，真值とな る検証データが必要である，そこで，FAOが標準化し， 推奨しているPenman-Monteith式（以下，FAO-56 PM 式） ${ }^{5)}$ にる基準蒸発散量を検証データとして用いる. 
$\mathrm{ASCE}^{6}$ も最適な基隻蒸発散量推定法としてPenmanMonteith式（以下，PM式）を推奨しているが，本論文で はFAO-56 PM式を用いる．なお，FAO-56 PM式の標準化 に際して，FAOが気象要素データに不足があるときの代 替式として推奨したのが，本論文で扱うHargreaves式で ある。

\section{(1) Penman-Monteith式}

PM式は, Penman式に群落抵抗, 空気力学的抵抗を加 えたものであり, Jensen et al. ${ }^{4} に$ にされたASCE PM式 (式(1)）が一般的である.

$$
E T_{o}=\frac{\Delta\left(R_{n}-G\right)+\frac{86400 \cdot \rho \cdot C_{p}\left(e_{s}^{o}-e_{a}\right)}{r_{a}}}{\lambda\left(\Delta+\gamma\left(1+\frac{r_{s}}{r_{a}}\right)\right)}
$$

$E T_{o}$ : 基準蒸発散量 $\left(\mathrm{mm} \cdot \mathrm{d}^{-1}\right), \Delta:$ 飽和水蒸気圧曲線 の勾配 $\left(\mathrm{hPa} \cdot{ }^{\circ} \mathrm{C}^{-1}\right), \gamma$ : 乾湿計定数 $\left(\mathrm{hPa} \cdot{ }^{\circ} \mathrm{C}^{-1}\right), \lambda$ : 蒸発潜熱 $\left(\mathrm{MJ} \cdot \mathrm{kg}^{-1}\right) ， R_{n}$ : 純放射量 $\left(\mathrm{MJ} \cdot \mathrm{m}^{-2} \cdot \mathrm{d}^{-1}\right)$, $G$ : 地中熱フラックス $\left(\mathrm{MJ} \cdot \mathrm{m}^{-2} \cdot \mathrm{d}^{-1}\right), \rho:$ 空気の密度 $\left(\mathrm{kg} \cdot \mathrm{m}^{-3}\right), C_{p}$ : 空気の定圧比熱 $\left(\approx 1.013 \cdot 10^{-3} \mathrm{MJ} \cdot \mathrm{kg}^{-1}\right.$ .$\left.{ }^{\circ} \mathrm{C}^{-1}\right), e_{s}^{o}$ : 飽和水蒸気圧 $(\mathrm{hPa}), e_{a}$ : 水蒸気圧 $(\mathrm{hPa}), r_{s}$ : 群落抵抗 $\left(\mathrm{s} \cdot \mathrm{m}^{-1}\right), r_{a}$ : 空気力学的抵抗 $\left(\mathrm{s} \cdot \mathrm{m}^{-1}\right)$

式(1)に含まれる $r_{s}, r_{a}$ などを草丈 $12 \mathrm{~cm}$, 群落抵抗 $70 \mathrm{~s} \cdot \mathrm{m}^{-1}$ ，アルベド0.23で同定したものが，本論文で扱う FAO-56 PM式 (式(2)) である.

$$
E T_{o}=\frac{0.408 \cdot \Delta\left(R_{n}-G\right)+\gamma \frac{900}{T+273} u_{2}\left(e_{s}^{o}-e_{a}\right)}{\Delta+\gamma\left(1+0.34 u_{2}\right)}
$$

$u_{2}:$ 地上 $2 \mathrm{~m}$ 高さでの風速 $\left(\mathrm{m} \cdot \mathrm{s}^{-1}\right)$

\section{(2) Hargreaves式}

Hargreaves式（以下，Hg式）は最高温度，最低気温の みを入力として基準蒸発散量を算出し ${ }^{7}$,

$$
\begin{aligned}
E T_{o} & =\varepsilon \cdot\left(32+1.8 T_{\text {mean }}\right) \cdot \frac{R_{s}}{\lambda} \\
& =\varepsilon \cdot\left(32+1.8 T_{\text {mean }}\right) \cdot k \sqrt{\Delta T} \cdot \frac{R_{a}}{\lambda}
\end{aligned}
$$

$\varepsilon$ : 係数 $\left({ }^{\circ} \mathrm{C}^{-1}\right) ， R_{s}$ : 全天日射量 $\left(\mathrm{MJ} \cdot \mathrm{m}^{-2} \cdot \mathrm{d}^{-1}\right)$, $T_{\text {mean }}$ : 月平均気温 $\left(=\left(T_{\max }+T_{\min }\right) / 2,{ }^{\circ} \mathrm{C}\right), T_{\max }$ : 月平 均最高気温 $\left({ }^{\circ} \mathrm{C}\right), T_{\min }$ : 月平均最高気温 $\left({ }^{\circ} \mathrm{C}\right), k$ : 係数 $\left({ }^{\circ} \mathrm{C}^{-0.5}\right), \Delta T$ : 月較差 $\left(=T_{\max }-T_{\min },{ }^{\circ} \mathrm{C}\right), R_{a}$ : 大気外日射量 $\left(\mathrm{MJ} \cdot \mathrm{m}^{-2} \cdot \mathrm{d}^{-1}\right)$

と表される. (4)式の係数 $\varepsilon$ を 0.0075 , 係数 $k$ を 0.17 とした ものが，一般的な $\mathrm{Hg}$ 式 (式(5)) となる ${ }^{8)}$.

$$
E T_{o}=0.0023 \cdot\left(T_{\text {mean }}+17.8\right) \sqrt{\Delta T} \cdot \frac{R_{a}}{\lambda}
$$

$\mathrm{Hg}$ 式は気温のみを入力データとすることから温度法に 分類されるが，実質的にはMakkink式と同じく放射温度
法の構造を有している.

\section{a) 係数k}

係数 kの推定法については多く報告されている99ねどが， 本論文では松井 ${ }^{10}$ が南西諸島，小笠原諸島を除く日本全 国67地点の 15 年間の全天日射量データと気象官署の所在 から求めた式(6)を用いる.

$$
k=0.1612 \cdot P^{-0.0409}
$$

$P$ : 海岸までの距離 $(\mathrm{km})$

南西諸島，小笠原諸島の気象官署では，島を囲む海の 影響により月較差 $\Delta T か ゙$ 緩和され，全天日射量の推定が 困難であることから本論文でも対象外とする.

b) 係数 $\varepsilon$

$$
\begin{aligned}
& \text { 式(6)を式(4)に代入すると，倸数をは } \\
& \varepsilon=\frac{E T_{o}}{\left(32+1.8 T_{\text {mean }}\right) \cdot\left(0.1612 \cdot P^{-0.0409} \sqrt{\Delta T} \cdot R_{a}\right)}
\end{aligned}
$$

により求めることができる. 式(7)からわかるように， $\varepsilon$ は月毎に変化する係数である. 松井 ${ }^{100}$ は小型蒸発計蒸発 量を検証データとして係数をの算定式を示しているが, 小型蒸発計蒸発量は物理的意味が曖昧であり, 提示され た算定式の利用は避けた方がよい，そこで，基隻蒸発散 量の推定に利用でき，かつ全国に適用可能な係数 $の$ 算 定式について3.で検討する.

\section{（3）比較する基準蒸発散量推定式}

$\mathrm{Hg}$ 式の有用性を確認するために, $\mathrm{Hg}$ 式と同じく気温 のみを入力とするThornthwaite式, Hamon式と比較対照 とする. 他にも, 気温だけから可能蒸発散量を推定する 式 ${ }^{11)}$ とて, Linacre式やBlaney-Criddle式などがあるが, 前者には露点温度, 後者には作物係数が必要であること から対象外とした。

\section{a) Thornthwaite式}

Thornthwaite式（以下，Th式）は式(8)により表される.

$$
E T_{T h}=0.533 \cdot D_{0}\left(10 T_{i} / J\right)^{a}
$$

$$
\left\{\begin{array}{l}
a=\left(492390+17920 J-77.1 J^{2}+0.675 J^{3}\right) \cdot 10^{-6} \\
J=\sum_{i=1}^{12}\left(T_{i} / 5\right)^{1.514}
\end{array}\right.
$$

$E T_{T h}: T h$ 式による蒝発散量 $\left(\mathrm{mm} \cdot \mathrm{d}^{-1}\right) ， D_{0}: i$ 月の可照 時間（12h.d $\mathrm{d}^{-1}$ を1とする）, $T_{i}$ ：（一般的な） $i$ 月の月平 均気温 $\left({ }^{\circ} \mathrm{C}\right)$

b) Hamon式

Hamon式（以下，Hm式）は式(9)により表される.

$$
E T_{H m}=0.14 \cdot D_{0}^{2} p_{t}
$$

$E T_{H m}: \mathrm{Hm}$ 式による蒸発散量 $\left(\mathrm{mm} \cdot \mathrm{d}^{-1}\right), p_{t}:$ 月平均気 温 $T_{i}$ に対する飽和絶対湿度 $\left(\mathrm{g} \cdot \mathrm{m}^{-3}\right)$ 
表-1 ステップワイズ重回帰分析により抽出された気象要素（上位3位まで）

\begin{tabular}{lcccccccc}
\hline & $T_{\max }$ & $T_{\min }$ & $T_{\operatorname{mean}}$ & $R H$ & $W$ & $R f$ & $\Delta T$ & $\sqrt{\Delta T}$ \\
\hline 当該要素が最も有用と & 9 & 2 & 0 & 19 & 25 & 3 & 1 & 0 \\
なる気象官署 & $(15 \%)$ & $(3 \%)$ & $(0 \%)$ & $(32 \%)$ & $(42 \%)$ & $(5 \%)$ & $(2 \%)$ & $(0 \%)$ \\
当該要素が二番目に有 & 0 & 6 & 0 & 2 & 5 & 11 & 19 & 16 \\
用となる気象官署 & $(0 \%)$ & $(10 \%)$ & $(0 \%)$ & $(3 \%)$ & $(9 \%)$ & $(19 \%)$ & $(32 \%)$ & $(27 \%)$ \\
当該要素が三番目に有 & 7 & 5 & 5 & 12 & 7 & 10 & 7 & 6 \\
用となる気象官署 & $(12 \%)$ & $(9 \%)$ & $(9 \%)$ & $(20 \%)$ & $(12 \%)$ & $(17 \%)$ & $(12 \%)$ & $(10 \%)$ \\
\hline
\end{tabular}

\section{（4）計算対象とする地点・期間}

計算の対象となる地点は, 南西諸島, 小笠原諸島の気 象官署を除き，FAO-56 PM式の適用に必要な気温，全天 日射量, 風速, 相対湿度が観測されている59地点とした。 計算期間は，気象庁年報の気候観測月別累年值（SMP） で前述4要素のデータが揃っている期間とし，ほとんど の地点で1970年代前半から2000年までの 25 年強である.

\section{Hargreaves式の係数 $\varepsilon$ 算定}

\section{および基準蒸発散量の推定結果}

$\mathrm{Hg}$ 式の係数 $の$ 算定方法は, 係数 $の$ 算定結果だけでな く，基準蒸発散量の推定結果と併せて検討する.

\section{(1) 算定に有用な気象要素}

係数 $\varepsilon$ 算定に有用な気象要素について検討するため, 月毎に求められる係数 $\varepsilon$ を目的変数, 月平均最高気温 $T_{\max }$ (以下, 最高気温), 月平均最低気温 $T_{\min }$ (以下, 最低 気温）, 月平均気温 $T_{\text {mean }}$ (以下, 平均気温）, 月較差 $\Delta T$, 月較差の平方根 $\sqrt{\Delta T}$, 月平均相対湿度 $R H$ (以下, 相対 湿度), 月平均風速 $W$ (以下，風速），月降水量 $R f$ を説 明変数としたステップワイズ重回帰分析（以下，重回帰 分析）を59地点全てについて行った. なお, 説明変数に ついては，実質的にHg式が分類される放射法あるいは 放射温度法の既往の研究4)や観測記録の蓄積の有無から 上記の8変数とした. 重回帰分析にて抽出された気象要 素のうち, 上位3位までの気象要素のまとめを表-1に示 寸.上位3位までで, 風速, 湿度がそれぞれ33地点, 37 地点と比較的多くの地点で抽出されていることがわかる. しかし, 上位3位までの気象要素の組み合わせで最多と なる (湿度, 風速, 月較差) でも7地点しかなく, 汎用 性に乏しい結果となった. また, その組み合わせに地域 的な偏在傾向は見られなかった.

\section{(2) 算定式および推定結果}

(1)において，汎用的な説明変数の組み合わせを見出 せなかったことから, 全地点の全データを1つのデータ セットとして, 係数 $の$ 算定式を求めることとした. 得 られた算定式を用いた基隻蒸発散量の推定結果はRMSE
（式(10)）, 決定係数 $R^{2}, 2 つ の$ 評価関数により評価する.

$$
R M S E=\sqrt{\frac{1}{N} \sum(P M-E s t)^{2}}
$$

$N:$ データ数, $P M:$ FAO-56 PM式による計算値, Est : Hg式による計算値

a) ケース0

Hargreavesが示したように係数 $\varepsilon$ を 0.0075 としたときの 推定結果を表-2中のケース0に示す．RMSEの平均が 0.42 , 決定係数 $R^{2}$ の平均が 0.92 となり, これらの值が以 下に示寸推定結果の基淮値となる.

b) ケース 1

説明変数を最高気温, 最低気温, 平均気温, 月較差, 月較差の平方根, 相対湿度, 風速, 月降水量の8つの気 象要素としたとき（ケース1）の算定式のまとめを表-3 (a)に示寸. 風速, 相対湿度, 月較差の平方根, 最低気温 の4つの気象要素が抽出されている．表-1で比較的高い 割合で抽出された相対湿度, 風速が含まれることで, 決 定係数 $R^{2}$ は0.6程度と良好な結果を示している. MartínezCob et al. ${ }^{12)}$ はHg式の係数が風速の影響を受けることを指 摘しており，その内容と符合する結果となっている。 ま た，得られた算定式を用いた基準蒸発散量の推定結果を 表-2中のケース 1 に示す. ケース 0 と比べて推定精度が 向上していることがわかる.

しかし, 説明変数に含まれる相対湿度, 風速は観測地 点が限られることから, 推定式の適用範囲が限られてし まう問題がある.

c) ケース 2

ケース 1 の結果をふまえ，多くの気象観測所で観測さ れている最高気温, 最低気温, 平均気温, 月較差, 月較 差の平方根, 月降水量, Allen et al. . $^{5}$ の方法で推定した相 対湿度 $R H$ の7つの気象要素を説明変数とした重回帰分 析を行った. Allen et al.の方法とは, 最低気温記録時に 相対湿度が $100 \%$ となり, 露点温度が最低気温と等しく なることを仮定して，最低気温から水蒸気圧を求め，そ の水蒸気圧と最高気温，最低気温からそれぞれ最小相対 湿度, 最大相対湿度を算出し, 最終的に平均相対湿度を 推定する方法である. この方法を用いて，地点毎に推定 した相対湿度の決定係数 $R^{2}$ は (平均土標準偏差) $=(0.50$

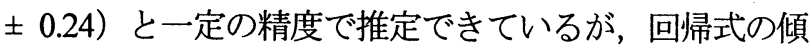
きは $(1.79 \pm 0.81)$, 同じく切片は $(-70.82 \pm 68.61)$ と 
表-2 基隻蒸発散量の推定結果

\begin{tabular}{lcc}
\hline & $R M S E$ & 決定係数 $R^{2}$ \\
\hline ケース 0 & $0.42 \pm 0.13$ & $0.92 \pm 0.06$ \\
ケース 1 & $0.34 \pm 0.07$ & $0.91 \pm 0.06$ \\
ケース 2 & $0.45 \pm 0.14$ & $0.89 \pm 0.07$ \\
ケース 3 & $0.42 \pm 0.11$ & $0.87 \pm 0.09$ \\
ケース 3, & $0.38 \pm 0.10$ & $0.89 \pm 0.07$ \\
ケース 4 & $0.31 \pm 0.10$ & $0.92 \pm 0.06$ \\
ケース 5 & $0.34 \pm 0.10$ & $0.92 \pm 0.06$ \\
\hline & & (平均標隻偏差)
\end{tabular}

表-3 ステップワイズ重回帰分析により得られた 係数

(a) $T_{\max }, T_{\min }, T_{\text {man }}, \Delta T, \sqrt{\Delta T}, R H, W, R f$ 説明変数としたとき

抽出された気象要素

\begin{tabular}{clcc}
\hline & 抽出された気象要素 & $R^{2}$ & $R^{2}$ 変化量 \\
\hline 1 & $W$ & 0.42 & 0.42 \\
2 & $W, R H$ & 0.52 & 0.10 \\
3 & $W, R H, \sqrt{\Delta T}$ & 0.59 & 0.08 \\
4 & $W, R H, \sqrt{\Delta T}, T_{\min }$ & 0.60 & 0.01 \\
\hline
\end{tabular}

(b) $T_{\text {max }}, T_{\text {min }}, T_{\text {mean }}, \Delta T, \sqrt{\Delta T}, R H ', R f$ を

説明変数としたとき

\begin{tabular}{|c|c|c|c|}
\hline & 抽出された気象要素 & $R^{2}$ & $R^{2}$ 変化量 \\
\hline 1 & $T_{\max }$ & 0.15 & 0.15 \\
\hline 2 & $T_{\max }, R H^{\prime}$ & 0.28 & 0.12 \\
\hline 3 & $T_{\max }, R H^{\prime}, \Delta T$ & 0.31 & 0.04 \\
\hline 4 & $T_{\max }, R H, \Delta T, R f$ & 0.33 & 0.02 \\
\hline
\end{tabular}

(c) $T_{\max }, T_{\min }, T_{\text {mean }}, \Delta T, \sqrt{\Delta T}, R H^{\prime}$ を 説明変数としたとき

\begin{tabular}{clcc}
\hline & 抽出された気象要素 & $R^{2}$ & $R^{2}$ 変化量 \\
\hline 1 & $T_{\max }$ & 0.16 & 0.16 \\
2 & $T_{\max }, R H^{\prime}$ & 0.29 & 0.12 \\
3 & $T_{\max }, R H^{\prime}, T_{\min }$ & 0.32 & 0.04 \\
4 & $T_{\max }, R H^{\prime}, T_{\min }, \sqrt{\Delta T}$ & 0.33 & 0.01 \\
\hline
\end{tabular}

(d) ケース 3 と同じ説明変数で，係数

\begin{tabular}{clcc} 
& 目的変数としたとき & \multicolumn{2}{c}{ (ケース $\left.{ }^{\prime}\right)$} \\
\hline \multicolumn{2}{l}{ 抽出された気象要素 } & $R^{2}$ & $R^{2}$ 変化量 \\
\hline 1 & $T_{\max }$ & 0.13 & 0.13 \\
2 & $T_{\max }, R H^{\prime}$ & 0.23 & 0.10 \\
3 & $T_{\max }, R H^{\prime}, T_{\min }$ & 0.24 & 0.01 \\
\hline
\end{tabular}

幅のある結果となっている.

このようにして推定した相対湿度を説明変数に加えた， 重回帰分析の結果を表-3 (b)に示す. 抽出された気象要 素は，有用な順に最高気温，推定した相対湿度，月較差， 降水量の4つとなっている. 得られた算定式を用いたと きの基準蒸発散量の推定精度（表-2中のケース 2）は, 両評価関数共にケース 0 より低下していることがわかる。 なかでも北海道内で大きく低下しており，RMSEの平均 はケース0での0.39から0.56（ケース 2) となっている. これは説明変数に降水量が含まれることから，梅雨のな い北海道とそれ以外の地点では年間の降水パターンが大

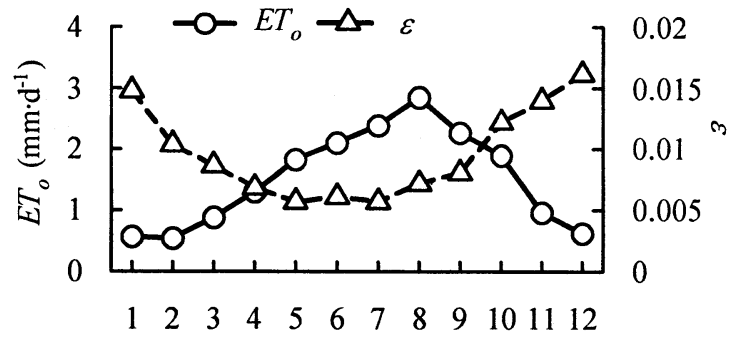

図-1＼cjkstart基準蒸発散量と係数 $\varepsilon$ (稚内, 2000年）

きく異なっていることが主因と考えられる.

d) ケース 3

ケース 2 の結果をふまえ，月降水量を除いた最高気温, 最低気温, 平均気温, 月較差, 月較差の平方根, 推定し た相対湿度の6つの気象要素を説明変数とした重回帰分 析を行った. 抽出された気象要素は有用な順に, 最高気 温, 推定した相対湿度, 最低気温, 月較差の平方根の 4 つである. 得られた算定式を用いたときの基準蒸発散量 の推定精度を表-2中のケース 3 に示す。 RMSEではケー ス 2 と比べると若干向上し, ケース 0 と同程度の結果と なっているものの, 決定係数 $R^{2}$ ではケース0 との差が拡 大する結果となっている.

ケース 3 のRMSEがケース 0 と同程度の結果しか示さ ない理由として，算定式の決定係数 $R^{2} か ゙ 0.33$ と高くない ことに加えて，次のことが考えられる. 図-1に例示する ように, 係数 $\varepsilon$ と基準蒸発散量の年変動パターンはほぼ 正反対となる. このため, 係数 $\varepsilon$ 算定式を重回帰分析 で求めた後に，その式を用いて基準蒸発散量との差を $R M S E$ で評価すると手法上の問題が生じる.つまり，係 数 $の$ 算定式を求める重回帰分析は基本的には相関係数 （または決定係数）を最大化する手法であり，相対的に 大きな区間での誤差を小さくするように働く，図-1から わかるように, 係数とが相対的に大きな值を示すのは冬 季であり, 基準蒸発散量が大きくなる夏季ではない.こ のため, 基準蒸発散量が大きな值を示す夏季の精度が低 下し，RMSEがさほど改善されていないと考えられる.

この問題に対する一方策として，重回帰分析の目的変 数を係数 $\varepsilon$ ではなく, 係数 $\varepsilon$ の逆数として分析を行った (ケース $\left.3^{\prime}\right)$ ），逆数ではなく，定数項（例えば，1.0) と係数 の差を目的変数とすることも考えられるが，逆 数の方がより効果的であると考えた. その結果, 抽出さ れた気象要素を表-3 (d)に，推定結果のまとめを表-2中の ケース 3'に示す. ケース 3 の結果と比べると, RMSE, 決定係数ともに向上していることがわかる. しかし， ケース 0 との比較では，RMSEを見ると $0.42 か ら 0.38$ と改 善しているものの，決定係数ではケース0に及ばない結 果となっている.

e) ケース 4

ケース 3 ’までの結果から，月毎に変化する係数 $\varepsilon$ 算 定式の導出には限界があると判断し，準Newton法を用 


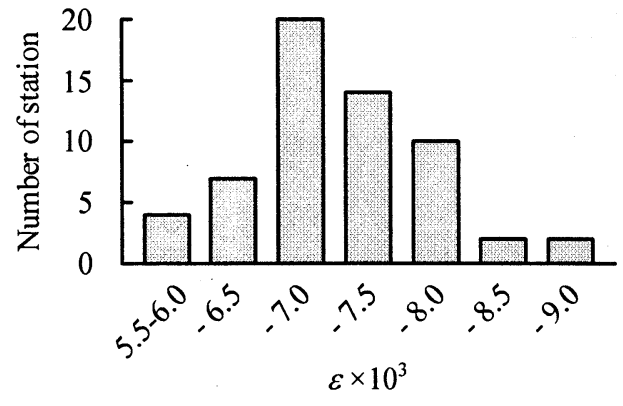

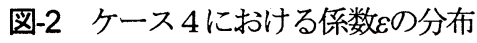

表-4 ステップワイズ重回帰分析により得られた 係数

\begin{tabular}{clcc}
\hline & 抽出された要素 & $R^{2}$ & $R^{2}$ 変化量 \\
\hline 1 & $\sqrt{\Delta T_{\text {all }}}$ & 0.30 & 0.30 \\
2 & $\sqrt{\Delta T_{\text {all }}}, P$ & 0.48 & 0.18 \\
3 & $\sqrt{\Delta T_{\text {all }}}, P, T_{\text {mean-all }}$ & 0.67 & 0.19 \\
\hline
\end{tabular}

いて地点毎にRMSEを最小化する係数 $\varepsilon$ （定数）を求めた. 求められた係数 きの推定結果のまとめを表-2中のケース 4に示す. ケー ス0 と比べると, 決定係数が同一となるのは当然として, RMSEが大きく改善されていることがわかる.

\section{f) ケース 5}

図-2からケース 4 で求められた係数 8 比較的広く分 布していることがわかる. そこで，ケース4で得られた 定数を目的变数, 各地点の緯度 $L t$, 経度 $L g$, 標高 $E l$, 対 象期間中の平均気温 $T_{\text {mean-all, }}$ 平均月較差 $\Delta T_{\text {all }}$, 平均月較 差の平方根 $\sqrt{\Delta T_{\text {all }}}$, 海岸までの距離 $P$ を説明変数として 重回帰分析を行った. 得られた算定式のまとめを表-4に 示す. 決定係数は 0.67 となり, 比較的高い精度で推定で きていることがわかる. しかし, 近年, 平均気温の上昇 や日較差の減少が指摘されており, 長期の月水収支分析 を行う際に平均気温や平均月較差を定数として扱うこと は現実的ではない，そこで，便宜的にそれぞれを当該年 の年平均気温 $T_{\text {mean-ann, }}$, 当該年の平均月較差 $\Delta T_{\mathrm{ann}}$ として係 数

$$
\begin{aligned}
\varepsilon= & \left(12.936-2.587 \cdot \sqrt{\Delta T_{\text {ann }}}\right. \\
& \left.+0.018 \cdot P+0.083 \cdot T_{\text {mean-ann }}\right) \cdot 10^{-3}
\end{aligned}
$$

式(11)を用いた基準蒸発散量の推定結果のまとめを表2中のケース 5 に示す. ケース 4 の精度には及ばないも のの, ケース0より大幅に精度が向上していることがわ かる.

\section{(3) 適応させたHargreaves式}

(2)の結果から，係数
表-5 年可能蒸発散量の百分率誤差のトレンド $\left(\% \cdot \mathrm{y}^{-1}\right)$

\begin{tabular}{lll}
\hline & 式(5) & 式(12) \\
\hline 盛 岡 & $-0.25^{* * *}$ & -0.06 \\
前 橋 & $-0.31^{*}$ & $-0.29^{*}$ \\
御前崎 & $-0.25^{*}$ & $-0.15^{*}$ \\
米 子 & -0.24 & -0.10 \\
潮 岬 & $-0.21^{*}$ & -0.11 \\
福 岡 & $-0.35^{* *}$ & -0.19 \\
宮 崎 & $-0.38^{* *}$ & -0.22 \\
高 松 & $-0.31^{* *}$ & -0.13 \\
\hline
\end{tabular}

検定はMann-Kendall検定によって行い,

* : 有意水準 $5 \%, * *$ : 同 $1 \%, * * *$ : 同0.1\%を表す.

と考えられる. したがって，本論文で提示する $\mathrm{Hg}$ 式は 式(4)に，式(6), 式(11)を代入した式(12)となる.

$$
\begin{aligned}
E T_{o}= & \left(12.936-2.587 \cdot \sqrt{\Delta T_{\text {ann }}}+0.018 \cdot P\right. \\
& \left.+0.083 \cdot T_{\text {mean-ann }}\right) \cdot 10^{-3} \times\left(32+1.8 T_{\text {mean }}\right) \\
& \times\left(0.1612 \cdot P^{-0.0409}\right) \cdot \sqrt{\Delta T} \cdot \frac{R_{a}}{\lambda}
\end{aligned}
$$

\section{4. 適応させたHargreaves式の有用性}

式(11)に示寸係数 $の$ 算定式の有用性を検討するために, 係数 8 を0.0075とする原式と比較を行う.そして，式(12) に示すHg式の有用性を検討するために，同じく気温を 入力データとするTh式, $\mathrm{Hm}$ 式との比較を行う.

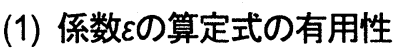

本論文では式(5)に示す一般的な $\mathrm{Hg}$ 式，式(12)に示す Hg式ともに, FAO-56 PM式の計算値を真値とした基淮 蒸発散量の推定式として扱っている. 推定式を長期の月 水収支分析に利用することを考えると，その推定誤差は ランダム誤差であるか, トレンドがあったとしてもより 小さいことが望まれる，そこで，FAO-56 PM式での計算 に必要な気象要素が25年以上欠測していない盛岡, 前橋, 御前崎, 米子, 潮岬, 福岡, 宮崎, 高松の8地点を対象 として，式(5)，式(12)それぞれにより求められる年可能 蒸発散量の百分率誤差について, Theil-Sen法 ${ }^{13}$ によるト レンドを求めた. その結果を表-5に示す，式(5)と式(12) の結果を比較すると, 対象とした8地点とも式(12)のトレ ンドの大きさが式(5)を下回っており，係数をを定数では なく，年変化する倸数として扱う式(11)の有用性を確認 できる.

なお，いずれの地点ともわずかではあるが減少トレン ドを示している. この理由として，PM式による基準蒸 発散量が明瞭な増加トレンドを示しているのに対して, Hg式による推定值がその増加割合に対応できていない ことが挙げられる.これについては今後の課題としたい. 


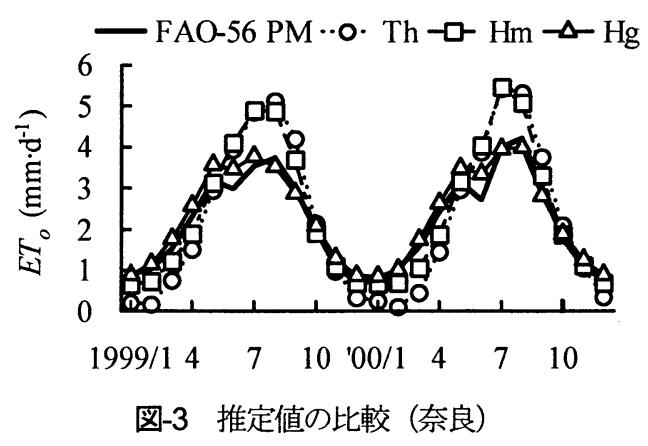

表-6 基隻蒸発散量推定式の比較

\begin{tabular}{lccc}
\hline & Th式 & Hm式 & Hg式 \\
\hline$R M S E$ & $0.89 \pm 0.12$ & $0.68 \pm 0.13$ & $0.34 \pm 0.10$ \\
$R^{2}$ & $0.86 \pm 0.05$ & $0.86 \pm 0.05$ & $0.92 \pm 0.06$ \\
\hline & & & (平均墂準偏差)
\end{tabular}

\section{(2) Thornthwaite式およびHamon式との比較}

Th式，Hm式，Hg式による計算結果の一例を図-3に, $R M S E$, 決定係数 $R^{2}$ のまとめを表-6に示す. 表-6から, いずれの評価関数でも $\mathrm{Hg}$ 式が優れていることがわかる. 地点別の結果では, Hg式がRMSEで59地点全て, 決定係 数でも59地点中54地点で最良となっている. 決定係数で $\mathrm{Hg}$ 式が最良とならなかった稚内, 銚子, 御前崎, 浜田, 清水の5地点においても, 最良な式と Hg式の差は最大で 0.02であり，遜色のない結果となっている.

$\mathrm{Hg}$ 式がこのような高い推定精度を示す理由としては, 蒸発散量の大小を規定する日射量を推定する項の存在が 大きいと考えられる. つまり, この項の存在により, Th 式やHm式の推定值が盛夏期をピークとして単調な動き をするのに対して, Hg式の推定值は鈍い反応ながらも 基準蒸発散量の変動に対応できていることが挙げられる.

\section{5. まとめ}

$\mathrm{Hg}$ 式は, 最高気温, 最低気温があれば高い精度で基 準蒸発散を推定することから，広範に利用されている. その改良も数多く報告されているが, $\mathrm{Hg}$ 式が式(5)の形 で表されることが多いため, 式(5)の係数が検討の対象と なることが多い．しかし， Hg式の開発経緯を考えると， 全天日射量の観測データがあればほぼ自動的に定まる倸 数 $k$, フィッティングを必要とする係数にに分けた方が合 理的に検討できると思われる.このような考えに基づき， 本論文では係数 まとめることができる.

(1) ステップワイズ重回帰分析により, 適用範囲の広い 係数 $\varepsilon$ 算定式として, 年平均月気温較差の平方根, 海からの距離, 年平均気温を変数とする重回帰式を 提示し, その有用性を確認した.
（2）気温のみを入力データとするTh式， Hm式，適応さ せた $\mathrm{Hg}$ 式を比較し, 適応させた $\mathrm{Hg}$ 式が優れており, RMSE $0.34 \pm 0.10 \mathrm{~mm} \cdot \mathrm{d}^{-1}$ (平均土標準偏差）の精度で 基準蒸発散量を推定できることを示した.

\section{参考文献}

1) Thornthwaite, C.W.: An approach toward a rational classification of climate, Geogr. Rev., Vol. 38, pp. 55-94, 1948.

2) Hamon, W.R.: Estimating potential evapotranspiration, $J$. Hydraulics Div., ASCE, Vol. 87, HY3, pp. 107-120, 1961.

3) Hargreaves, G.H. and Allen, R.G.: History and evaluation of Hargreaves evapotranspiration equation, J. Irri. Drain. Eng., Vol. 129 (1), pp. 53-63, 2003.

4) Jensen, M.E., Burman, R.D. and Allen, R.G.: Evapotranspiration and irrigation water requirements, ASCE Manuals and Reports on Engineering Practice No. 70, ASCE, 1990.

5) Allen, R.G., Pereira, L.S., Raes, D. and Smith, M.: Crop evapotranspiration, FAO Irrigation and Drainage Paper No. 56, FAO, 1998.

6) Allen, R.G., Walter, I.A., Elliott, R., Mecham, B., Jensen, M.E., Itenfisu, D., Howell, T.A., Snyder, R., Brown, P., Eching, S., Spofford, T., Hattendorf, M., Cuenca, R.H., Wright, J.L. and Martin, D.: Issues, requirements and challenges in selecting and specifying a standardized ET equation, Proc. 4th National Irrigation Symp., ASAE, pp. 201-208, 2000.

7) Hargreaves, G.H. and Samani, Z.A.: Estimating potential evapotranspiration. J. Irri. and Drain. Div., ASCE, Vol. 108 (IR3), pp. 225-230, 1982.

8) Hargreaves, G.H. and Samani, Z.A.: Reference crop evapotranspiration from temperature. Appl. Eng. Agric, Vol.1 (2), pp. 96-99, 1985.

9) Allen, R.G.: Self-calibrating mcthod for cstimating solar radiation from air temperature, J. Hydrologic Eng., Vol. 2 (2), pp. 56-67, 1997.

10) 松井宏之 : Hargreaves式に基づく月平均蒸発計蒸発量の推 定, 水文・水資源学会誌, Vol.16(6), pp. 1-7, 2003.

11) $\mathrm{Xu}, \mathrm{C.Y}$. and Singh, V.P.: Evaluation and generalization of temperature-based methods for calculating evaporation, Hydrol. Process., Vol. 15, pp. 305-319, 2001.

12) Martínez-Cob, A. and Tejero-Juste, M.: A wind-based qualitative calibration of the Hargreaves ET0 estimation equation in semiarid regions, Agric. Water Manage., Vol. 64 (3), pp. 251-264, 2004.

13) Hirsch, R.M., Slack, J.R. and Smith, RA.: Techniques of trend analysis for monthly water quality data, Water Resources Res., Vol. 18(1), pp.107-121, 1982.

(2004.9. 30 受付) 